\title{
Physician Perspectives on Mammography Screening for Average-Risk Women: "Like a Double-Edged Sword"
}

\author{
Sophia Siedlikowski, MSc, Roland Grad, MD, CM, MSc, FCFP, Gillian Bartlett, PhD, \\ and Carolyn Ells, $\mathrm{PhD}$
}

Background: On balance, the benefits and harms of mammography screening put systematic screening for average-risk women into question. Since screening decisions frequently occur in primary care, it is important to understand what family physicians think of the evidence on mammography screening, and how they intend to use this information in practice.

Methods: Using a cross-sectional design, we obtained data from a group of physician participants who rated the daily Patient-Oriented Evidence that Matters (POEM), which is a short, research-based synopsis. Physicians responded to closed and open-ended questions, based on the validated Information Assessment Method. Quantitative data were assessed with descriptive statistics. The qualitative data were subjected to inductive and deductive iterative thematic analysis. These data were organized into subthemes, and then grouped into major themes.

Results: Four relevant POEMs were identified. Each of these POEMs was rated by 1243 to 1351 physicians, and these ratings provided 310 comments. Three major themes emerged across all 4 POEMs: 1) perspectives on information presented in POEMs, 2) applying this information in practice, and 3) confronting clinical and cultural realities. Our findings highlight important differences in the ways physicians value research-based information on mammography screening and use this information in their practice.

Conclusions: Although POEMs about mammography screening raise awareness of harms and benefits, deeply rooted ideas illustrate how any change process is complex. In sum, rethinking breast cancer screening for average-risk women is challenging. ( $\mathrm{J}$ Am Board Fam Med 2020;33:871-884.)

Keywords: Breast Cancer, Clinical Decision Making, Cross-Sectional Studies, Decision Making, Early Detection of Cancer, Family Physicians, Mammography, Primary Health Care, Women's Health

\section{Background}

To encourage early detection and thereby reduce mortality from breast cancer, population-based screening programs exist in many high-income countries.

This article was externally peer reviewed.

From the Department of Family Medicine, McGill University, Quebec, Canada (SS, GB, CE); Herzl Family Practice Centre, Department of Family Medicine, McGill University, Quebec, Canada (RG); School of Population and Global Health, McGill University, Quebec, Canada (CE); Family and Community Medicine, University of Missouri (GB).

Funding: Support for this work was received through research grants provided to GB by the Quebec Breast Cancer Foundation, titled "Connaître et communiquer son histoire familiale pour mieux lutter contre le cancer du sein au Québec: Mise en place d'une campagne d'information." Financial support for work on the POEMs database is received from Joule, Inc. (a subsidiary of the Canadian Medical Association) "Evaluating the effect of information technology on medical practice" project. McGill University receives these funds with $\mathrm{RG}$ as the nominated principal investigator.
When women do not present with a specific genetic susceptibility, family history, previous breast neoplasia, or chest irradiation, they are considered at average risk of getting breast cancer. ${ }^{1}$ For these women, mammography screening programs were widely implemented in Canada in the $1990 \mathrm{~s},{ }^{2}$ yet their worth is increasingly questioned due to growing awareness of the harms of screening average-risk women. ${ }^{3-5}$ Mammography screening has become so contentious that an independent medical board in Switzerland recommended abolishing their screening program. ${ }^{6}$ In France, a review recommended either abolishing or implemen-

Conflict of interest: None.

Corresponding author: Sophia Siedlikowski, MSc, Department of Family Medicine, McGill University, 5858 Côte-des-Neiges Rd, Montreal, Quebec H3S 1Z1, Canada (E-mail: sophia. siedlikowski@mcgill.cahealth.com). 
ting a reformed version of their current program. ${ }^{7}$ In Canada, publicly funded screening programs remain in place in 2020.

While mammography is done in radiology settings, a decision to undertake mammography screening is often made in primary care office practice. It is therefore vital to examine physician perspectives on screening of average-risk women, with respect to the complex literature on the harms and benefits of this test.

Questions about the true benefit of mammography have led to substantial debate. Twenty years after the randomized controlled trials evaluating mammography as a screening tool in Sweden, ${ }^{8}$ a follow-up statistical analysis linking the published data from these trials to the Swedish Cancer and Cause of Death Registers found a $15 \%$ relative reduction in breast cancer mortality due to regular screening by mammography. ${ }^{9}$ Other systematic reviews have, however, nuanced such findings. One Cochrane review of 7 trials that included 600,000 women found that screening likely reduced breastcancer mortality but the magnitude is uncertain because of methodological shortcomings of the included trials. ${ }^{10}$ The authors concluded that mammography screening does not clearly do more good than harm, thus underlining important ethical implications for clinical practice. ${ }^{10}$ Furthermore, expressing mortality reduction from screening using relative risk results in exaggerated perceptions of the true benefit of screening, which may hinder informed decision making. ${ }^{11}$ In 2012, the Independent United Kingdom Panel on Breast Cancer Screening reported the absolute risk reduction in breast cancer mortality due to screening ranged from $0.05 \%$ to $1 \% .^{12}$ The number of women who need to be screened to prevent 1 death from breast cancer further illustrates the limited ability of mammography to reduce breast cancer mortality. In women aged 40 to 49,50 to 59,60 to 69 , and 70 to 74 years, the numbers needed to screen over a median time of 7 years are $1724,1333,1087$, and 645 , respectively. ${ }^{13}$

In general, physicians are thought to overestimate the benefits of cancer screening tests. ${ }^{14}$ In a survey of over 400 primary care providers in the United States, nearly half of the physicians responded that detecting more cancer cases in a screened population as compared with an unscreened group proved that the screening test saved lives. ${ }^{15}$ Furthermore, although the College of Family Physicians of Canada and Canadian Medical Association recommend against routine mammography for average-risk women age
40 to 49 years as per the Canadian Task Force on Preventive Health Care (CTFPHC) guidelines, ${ }^{16}$ $22 \%$ of Canadian women age 40 to 49 received a screening mammogram, despite being of average risk. ${ }^{17}$

In addition to concerns regarding the magnitude of the benefit of mammography screening, systematic screening for average-risk women has been questioned due to overdiagnosis. In mammography screening, overdiagnosis occurs for those breast cancers that would not have harmed women during their lifetimes had they not been detected and treated. ${ }^{18}$ Overdiagnosed individuals undergo unnecessary testing and treatment for cancers that would not have caused disability or death if left untreated. ${ }^{19}$ Estimates of breast cancer overdiagnosis from screening mammography range widely from $0 \%$ to $30 \% .{ }^{20}$ Other studies have reported estimates of breast cancer overdiagnosis as high as $50 \% .^{16,21,22}$ This substantial range can be explained by disagreement on appropriate methods to calculate such estimates. ${ }^{23}$ For example, researchers use different denominators in their formula to estimate rates of overdiagnosis. ${ }^{24}$ Some researchers use the number of diagnoses during the screening period as a denominator while others use the number of diagnoses in the remaining lifetime. The latter option for calculating overdiagnosis leads to lower estimates. In the case of prostate cancer, overdiagnosis estimates range from $1.7 \%$ to $67 \%$ due to differences in calculation methods, population characteristics, and screening protocols. ${ }^{25}$ Several organizations have taken steps to address concerns regarding overdiagnosis.

The international Choosing Wisely campaigns, for example, aim to engage health care professionals and patients to make more appropriate and effective care choices. ${ }^{26}$ In 2014, Choosing Wisely Canada supported a recommendation against routine mammography screening for average-risk women aged 40 to 49 years, based on a 2011 systematic review performed for the CTFPHC. ${ }^{16}$ In 2018, the CTFPHC updated this breast cancer screening guideline. ${ }^{13}$ For the first time, their review systematically examined literature on women's values and preferences about screening. In their update, the CTFPHC continued to recommend against screening with mammography for women aged 40 to 49 years and specified that any decision to undergo screening should be conditional on the relative value a woman places on possible benefits and harms. The 2016 United States Preventive Services 
Task Force (USPSTF) breast cancer screening guidelines mostly align with those of the CTFPHC. The USPSTF advises that a woman's decision to start screening before age 50 years should be an individual choice. In women aged 50 to 74 years, they recommended biennial screening. Overall, their 2016 recommendations closely resemble their 2009 recommendations. Ebell et $\mathrm{al}^{27}$ compared mammography guidelines among 21 high-income countries including the United States and Canada. They showed that guidelines from specialty societies such as the American College of Radiology often support more frequent screening. Although the influence of practice guidelines on mammography screening practice is well established, ${ }^{28-31}$ many physicians find guideline recommendations to be conflicting $^{32}$ or unclear. ${ }^{33}$

Given that primary care physicians can have an important impact on the decisions of women considering cancer screening, ${ }^{34}$ it becomes important to understand their perspectives on the research that informs practice guidelines. Our study therefore aimed to explore physician perspectives on researchbased information about mammography screening for average-risk women. We report on what physicians thought of this research-based information, and how they intended to use it in their clinical practice.

\section{Methods}

We obtained data from a group of physicians who read and reacted to Patient-Oriented Evidence that Matters (POEMs) in a nationwide continuing medical education (CME) program. These data were selected to address the study aims with a cross-sectional design.

\section{Data Source: POEMs Database}

Since 2005, physician members of the Canadian Medical Association (CMA) can subscribe to receive the Daily POEM via e-mail. Each POEM concisely describes recently published primary research or systematic reviews. Described elsewhere, the Daily POEM selection process involves a review of all studies published monthly in 102 journals to identify new clinical research relevant to primary care. ${ }^{35}$ Accredited in Canada in 2006, the POEMs CME program requires participating physicians to reflect on the information in the Daily POEM. Through this program, physician members of the CMA earn a mini-credit from the College of Family Physicians of Canada (0.1
Mainpro-M1) or the Royal College of Physicians and Surgeons of Canada (0.25 Maincert Section 2). Researchers examined the profile of the physicians who rated POEMs in $2014 .{ }^{36}$ Out of 3718 physician raters, $77 \%$ were general practitioners or family physicians, and $67 \%$ were general practitioners or family physicians in full-time or part-time practice.

Physician reflections on each POEM are documented in a short questionnaire that includes closed and open-ended questions. The questions are based on the Information Assessment Method (IAM) ${ }^{37}$ and the IAM has documented validity. ${ }^{38}$ Its 4 main questions target the following domains or constructs: cognitive impact, relevance of this clinical information to a specific patient, the use or application of this clinical information, and if applied in practice, any expected health benefits (see Appendix A for a blank IAM questionnaire).

\section{Data Collection}

A search of the POEMs database in Essential Evidence Plus was conducted on June 5, 2017 for the period January 1, 2012 to June 5, 2017 using the term, "breast neoplasm." This search was done to retrieve all relevant POEMs relating to harms and benefits of mammography screening, screening decision making, and breast cancer overdiagnosis. We updated our search on May 25, 2020 searching the resource from 2012 to 2020 . A database of all IAM questionnaires received in the POEMs CME program was then searched to extract data for the retrieved POEMs.

\section{Quantitative Data}

Relevant to this study, the IAM questions and subitems of interest are found in Table 1. Frequency counts and percentages were calculated for 3 IAM questions and 9 items.

\section{Qualitative Data}

Perspectives were extracted from the 2 free text comment boxes in the IAM questionnaire. In Q1, when physicians responded "Yes" to the question, "This information is potentially harmful," they are asked to describe how this information may be harmful. A second and final free text box prompts physicians to further comment on the POEM. Note that physicians were unable to see comments submitted by their colleagues. 


\begin{tabular}{|c|c|}
\hline Domain & Question Sub-Item of Interest \\
\hline $\begin{array}{l}\text { Q1: What is the impact of this information on } \\
\text { you or your practice? }\end{array}$ & $\begin{array}{l}{ }^{\circ} \text { I disagree with the content of this information } \\
\text { This information is potentially harmful }\end{array}$ \\
\hline $\begin{array}{l}\text { Q3: Will you use this information for a specific } \\
\text { patient? }\end{array}$ & $\begin{array}{l}\text { If YES, then: } \\
{ }^{\circ} \text { As a result of this information I will manage this patient differently } \\
{ }^{\circ} \text { I had several options for this patient, and I will use this information to justify a } \\
\text { choice } \\
{ }^{\circ} \text { I thought I knew what to do, and I used this information to be more certain } \\
\text { about the management of this patient } \\
\text { I used this information to better understand a particular issue related to this } \\
\text { patient } \\
\text { I will use this information in a discussion with this patient, or with other } \\
\text { health professionals about this patient } \\
{ }^{\circ} \text { I will use this information to persuade this patient, or to persuade other health } \\
\text { professionals to make a change for this patient. }\end{array}$ \\
\hline $\begin{array}{l}\text { Q4: For this patient, do you expect any health } \\
\text { benefits as a result of applying this information? }\end{array}$ & $\begin{array}{l}\text { If YES, then: } \\
\text { This information will help to avoid unnecessary or inappropriate treatment, } \\
\text { diagnostic procedures, preventative interventions or a referral, for this patient }\end{array}$ \\
\hline
\end{tabular}

IAM, Information Assessment Method.

\section{Data Analysis}

\section{Quantitative Data}

Frequency counts and percentages for each questionnaire item were compared between POEMs. Similarities and differences between frequencies for various items were reported descriptively.

\section{Qualitative Data}

Thematic analysis was conducted to identify, analyze, and report patterns within the data, following Braune and Clarke. ${ }^{39}$ The research team used judgment to identify themes that captured important elements in the data that responded to the research question. We sought to provide a rich description of the entire data set, since not much is known about physician perspectives on research-based information about mammography screening for average-risk women. One team member read and reread the data, translated any French language comments into English, and then coded all qualitative data from each of the POEMs manually. These initial codes were iteratively refined and NVivo 11.4.1 $1^{40}$ was used to reorganize them as updated codes. Each code was then tagged to its corresponding POEM. During this phase, a meeting was held with team member RG, to clarify the meaning of selected comments.

These updated codes were then analyzed using a combined inductive and deductive approach involving iterative coding and categorization of codes into subthemes, and major themes. We used the concept of "constructive feedback" to help guide the analysis of comments that specifically touched on the quality of the evidence summarized in a POEM. ${ }^{41}$ Constructive feedback categorizes such comments into 4 elements: a request for additional content, reservation or disagreement, contradictory evidence, and need for clarification. Two team members organized all the remaining codes into an initial list of subthemes and major themes. This list was finalized and refined through an iterative process involving meetings with a second pair of authors until all authors reached consensus. Any points of overlap across the major themes were also sought.

Only data relevant to the study question were retained. For consistency, a physician referring to women at "low-risk" of developing breast cancer was considered equivalent to a physician referring to women at average-risk of developing breast cancer.

\section{Results}

Four POEMs were retrieved from the Essential Evidence Plus database for the period 2012 to 2020. Table 2 presents a summary of the content of these POEMs (see Appendix B for complete POEMs).

\section{Quantitative Data}

Concerning the 4 POEMs on mammography screening, the number of POEM ratings (completed questionnaires) ranged from 1243 to 1351 . 
Table 3 summarizes data from these IAM questionnaires, showing the number and frequency of endorsements for the IAM items of interest.

Of the physicians who answered, "Yes" to using the information for a specific patient (Q3), the item in Q3 that was most frequently endorsed was, "I will use this information in a discussion with this patient, or with other health professionals about this patient." The frequencies for endorsement for this item were $56 \%, 63 \%, 63 \%$, and $54 \%$ for POEMs 1, 2, 3, and 4, respectively. This was the only item across all POEMs that garnered more than $50 \%$ of endorsement from physicians who had responded, "Yes" to the question on using this information for a specific patient. Across all 4 POEMs, of the physicians who indicated they would use the research-based information for a specific patient, $7.6 \%$ to $15.8 \%$ said they would use the information to manage the patient differently, and approximately the same proportion of physicians said they would use the information to persuade the patient or other health professionals to make a change for a patient.

In POEMs 1, 2, and 3, of the physicians who answered, "Yes" to Q3, over $85 \%$ endorsed the item from Q4: "this information will help to avoid unnecessary or inappropriate treatment, diagnostic procedures, preventative interventions or a referral, for this patient." In POEM 4, over 70\% of physicians endorsed this item.

\section{Qualitative Data}

Three hundred and ten comments from physicians who rated the information in these 4 POEMs were extracted. Table 4 presents the number of physician ratings and comments for all 4 POEMs.

Three major themes were identified from physicians' comments: 1) perspectives on information presented in POEMs, 2) applying this information in practice, and 3) confronting clinical and cultural realities. Figure 1 presents a Venn diagram of the analyses of physician comments across all 4 POEMs by theme. Each of these 3 themes is comprised of a number of subthemes, which themselves were created through the assembly of similar codes. Some subthemes overlapped 2 themes. One overlapped all 3 themes. Given the total number of comments, the comments that we elaborate on below are not tied to a specific POEM. Therefore, throughout this manuscript, the mention of a physician's thoughts on a
POEM refers to a physician's response to any of the 4 POEMs for which responses were analyzed.

\section{Theme 1: Perspectives on Information Presented in POEMS}

Theme 1 addresses physician perspectives on the research-based information itself. Physicians expressed diverse perspectives on the information in each POEM. Physicians seemed pleased that these POEMs presented a balanced view on screening. In reflecting on the decision making approach proposed in 1 POEM, 1 physician commented:

"I myself strongly support this approach, and am glad more balance is reported in how to approach this volatile subject." - POEM 3

The meaning of the information presented in the POEMs, however, was not always clear to physicians. Several physicians asked for clarification of concepts in the POEMs. For example, some physicians did not understand the concept of a benign cancer and questioned how one could know whether or not a cancer would progress. Several physicians mentioned they would need to read the original article to better understand the information in the POEM. Physicians also expressed a need for further research, to obtain clearer practical guidance.

"So now the epidemiologists need to say what really is the best thing to do, and do that soon!" - POEM 3

Numerous comments from physicians had to do with questioning the value of mammography screening and whether screening should still be recommended, given the research-based information. Others, however, showed great concern about potential harms of this research-based information, for instance, discussing the topic of overdiagnosis with women.

"Patients after hearing about this information may be reluctant to seek medical advice." - POEM 1

Research-based information sometimes led to confusion among doctors. Indeed, some physicians found the research-based information contradictory with information they had read from other sources.

"This information contradicts current practices and many other papers, however, I will need to review the paper more thoroughly in order to determine what, if any, impact it may have on current practices." POEM 2

Finally, many comments elaborated on concerns related to the quality and reporting of the research summarized by the POEM, such as methodological flaws, missing information, or problems in the representativeness of the study sample. 
Table 2. Key Characteristics of Four Retrieved POEMs Relevant to Mammography Screening, Decision Making, and Overdiagnosis

\begin{tabular}{|c|c|c|c|}
\hline POEM Title and Date & $\begin{array}{l}\text { Study Design } \\
\text { Publication Date }\end{array}$ & Clinical Question & Bottom Line \\
\hline $\begin{array}{l}\text { 1. Overdiagnosis of breast cancer is } \\
\text { common } 2013-01-29^{42}\end{array}$ & $\begin{array}{l}\text { Cohort } \\
\text { (prospective) } \\
2012\end{array}$ & $\begin{array}{l}\text { What proportion of breast } \\
\text { cancer is overdiagnosed? }\end{array}$ & $\begin{array}{l}\text { In the past } 30 \text { years we have seen } \\
\text { a large increase in the } \\
\text { detection of early-stage } \\
\text { cancers, but little } \\
\text { corresponding decline in late- } \\
\text { stage cancers. The authors } \\
\text { conclude that approximately } 1 \\
\text { in } 4 \text { breast cancers has been } \\
\text { overdiagnosed, and was } \\
\text { unlikely to have ever harmed } \\
\text { the woman. }\end{array}$ \\
\hline $\begin{array}{l}\text { 2. Numbers to help women understand } \\
\text { the benefits/harms of screening } \\
\text { mammography 2014-02-14 }\end{array}$ & $\begin{array}{l}\text { Special } \\
\text { Communication } \\
2014\end{array}$ & $\begin{array}{l}\text { What are the trade-offs of } \\
\text { benefits and harms for women } \\
\text { considering a mammogram to } \\
\text { screen for breast cancer? }\end{array}$ & $\begin{array}{l}\text { The authors suggest that } \\
\text { balanced discussions about the } \\
\text { benefits and harms of } \\
\text { screening mammography } \\
\text { should focus not only on the } \\
\text { possibility of breast cancer } \\
\text { deaths avoided but also the } \\
\text { possibility of false alarms and } \\
\text { overdiagnosis (the detection of } \\
\text { abnormalities that will never } \\
\text { progress enough to cause } \\
\text { symptoms or death during a } \\
\text { patient's lifetime). The } \\
\text { numbers for women of } \\
\text { different ages are outlined in } \\
\text { the synopsis. Although some } \\
\text { women are comfortable with a } \\
\text { high rate of false positive } \\
\text { results, some women will } \\
\text { experience lasting } \\
\text { consequences } 43 \text { and should } \\
\text { know the risk of harm when } \\
\text { making the decision whether } \\
\text { to screen. }\end{array}$ \\
\hline $\begin{array}{l}\text { 3. Mammography doesn't decrease } \\
\text { cancer-related deaths long term 2014- } \\
04-16^{44}\end{array}$ & $\begin{array}{l}\text { Randomized } \\
\text { controlled trial } \\
\text { (non-blinded) } \\
2014\end{array}$ & $\begin{array}{l}\text { Over the long term, does } \\
\text { screening mammography } \\
\text { decrease the likelihood of a } \\
\text { woman dying of breast } \\
\text { cancer? }\end{array}$ & $\begin{array}{l}\text { Over an average follow up of } \\
22 \text { years in almost } 90,000 \\
\text { women, there was a clinically } \\
\text { insignificant difference of } 5 \\
\text { deaths due to breast cancer } \\
(500 \text { vs } 505) \text { in women who } \\
\text { received } 5 \text { annual screening } \\
\text { mammograms instead of usual } \\
\text { care. Over more than } 2 \\
\text { decades, only } 1.1 \% \text { of women } \\
\text { died of breast cancer, much } \\
\text { lower than the } 12.5 \% \text { ( } 1 \text { in } 8) \\
\text { often cited. }\end{array}$ \\
\hline $\begin{array}{l}\text { 4. Mammogram decision aid slightly } \\
\text { increases informed decisions by } \\
\text { women } 2015-08-13^{45}\end{array}$ & $\begin{array}{l}\text { Randomized } \\
\text { controlled trial } \\
\text { (double-blinded) } \\
2015\end{array}$ & $\begin{array}{l}\text { Does a decision aid that } \\
\text { incorporates data on breast } \\
\text { cancer overdiagnosis increase } \\
\text { informed decision making in } \\
\text { women? }\end{array}$ & $\begin{array}{l}\text { Decisions aids, regardless of } \\
\text { whether they contain } \\
\text { information about breast } \\
\text { cancer overdiagnosis, have a } \\
\text { modest influence on a } \\
\text { woman's ability to make } \\
\text { informed choices about } \\
\text { screening. }\end{array}$ \\
\hline
\end{tabular}

POEM, Patient-Oriented Evidence that Matters.

Theme 2: Applying This Information in Practice

Theme 2 addresses physician thoughts about the applicability of this information in their practice. Physicians expressed varying opinions. For example, several physicians reported how this research-based information would be useful in counseling women, especially having access to numbers and statistics to share with their patients. 


\begin{tabular}{|c|c|c|c|c|}
\hline \multirow[b]{2}{*}{ IAM Question } & \multicolumn{4}{|c|}{ Number of Physicians Endorsing Item (\%) } \\
\hline & $\begin{array}{l}\text { POEM } 1 \\
\mathrm{n}=1293\end{array}$ & $\begin{array}{l}\text { POEM } 2 \\
\mathrm{n}=1351\end{array}$ & $\begin{array}{l}\text { POEM } 3 \\
\mathrm{n}=1308\end{array}$ & $\begin{array}{l}\text { POEM } 4 \\
\mathrm{n}=1243\end{array}$ \\
\hline Q1.I disagree with the content of this information. & $19(1.5)$ & $7(0.5)$ & $15(1.15)$ & $4(0.3)$ \\
\hline This information is potentially harmful. & $24(1.9)$ & $4(0.3)$ & $13(1.0)$ & 0 \\
\hline Q3.Will you use this information for a specific patient? & $139(10.8)$ & $214(15.8)$ & $156(11.9)$ & $79(6.4)$ \\
\hline Answering 'Yes' to Q3 enables the following sub-items: & $\mathrm{n}=139$ & $\mathrm{n}=214$ & $\mathrm{n}=156$ & $\mathrm{n}=79$ \\
\hline As a result of this information I will manage this patient differently. & $22(15.8)$ & $19(8.9)$ & $19(12.2)$ & $6(7.6)$ \\
\hline $\begin{array}{l}\text { I had several options for this patient, and I will use this information to justify a } \\
\text { choice. }\end{array}$ & $33(23.7)$ & $50(23.4)$ & $44(28.2)$ & $19(24.1)$ \\
\hline $\begin{array}{l}\text { I thought I knew what to do, and I used this information to be more certain } \\
\text { about the management of this patient. }\end{array}$ & $18(12.9)$ & $33(15.4)$ & $24(15.4)$ & $16(20.3)$ \\
\hline $\begin{array}{l}\text { I used this information to better understand a particular issue related to this } \\
\text { patient. }\end{array}$ & $52(37.4)$ & $61(28.5)$ & $49(31.4)$ & $34(43.0)$ \\
\hline $\begin{array}{l}\text { I will use this information in a discussion with this patient, or with other health } \\
\text { professionals about this patient. }\end{array}$ & $78(56.1)$ & $134(62.6)$ & $99(63.5)$ & $43(54.4)$ \\
\hline $\begin{array}{l}\text { I will use this information to persuade this patient, or to persuade other health } \\
\text { professionals to make a change for this patient. }\end{array}$ & $21(15.1)$ & $16(7.5)$ & $14(9.0)$ & $8(10.1)$ \\
\hline $\begin{array}{l}\text { Q4. For this patient, do you expect any health benefits as a result of applying } \\
\text { this information? }\end{array}$ & $121(87.1)$ & $186(86.9)$ & $129(82.7)$ & $61(77.2)$ \\
\hline Answering 'Yes' to Q4 enables the following sub-item: & $\mathrm{n}=121$ & $\mathrm{n}=186$ & $\mathrm{n}=129$ & $\mathrm{n}=61$ \\
\hline $\begin{array}{l}\text { This information will help to avoid unnecessary or inappropriate treatment, } \\
\text { diagnostic procedures, preventative interventions or a referral, for this } \\
\text { patient. }\end{array}$ & $105(86.8)$ & $163(87.6)$ & $122(94.6)$ & $45(73.8)$ \\
\hline
\end{tabular}

POEM, Patient-Oriented Evidence that Matters.

"These are powerful statistics to use in day to day practice. This information is especially belpful in counselling women who prefer less frequent screening mammograms." - POEM 2

In contrast, other physicians were uncertain about the value of the information in the POEMs and whether or not it would improve screening discussions.

"Looking at the numbers, I am not sure I can arrive at a decision confidently. I am not sure I can help my patients to make their decision!" - POEM 3

Physicians had varying levels of willingness to share this information with their patients. While some thought the information in the POEM should be shared, others thought it should only be shared if the patient was reluctant to screen or if the patient brought up this information. Finally, physicians mentioned the difficulty of having discussions about the information presented in some of the POEMs due to factors external to the patientprovider relationship.

"There is no opportunity to discuss this with patients in the current political environment of women's bealth" - POEM 2
Such challenges impeding physicians' and patients' ability to have balanced discussions about mammography screening are further explored in the third and final theme of this analysis.

\section{Theme 3: Confronting Clinical and Cultural Realities}

The third theme speaks to the clinical and cultural realities that physicians face, and how these issues have an impact on their capacity to think about and apply the research-based information in their practice. Physicians expressed that the practice of screening mammography remains the standard of care and that mammography is still recommended despite this research-based information. In addition, physicians highlighted the difficulty of presenting the limited benefits of mammography to women because mammography has been the norm for so long and there is much media to encourage it. Furthermore, comments elaborated on the particularly emotional nature of mammography screening and how emotions such as fear of cancer influence screening decisions. Physicians also spoke about the power that anecdotes have in women's decision making. 
Table 4. Number of Physician Ratings and Comments per POEM

\begin{tabular}{lrrrr}
\hline POEM & \multicolumn{1}{c}{1} & \multicolumn{1}{c}{3} & \multicolumn{1}{c}{4} \\
\hline Number of ratings & 1293 & 1351 & 1308 & 1243 \\
Number of comments & 29 & 125 & 93 & 63 \\
\hline
\end{tabular}

POEM, Patient-Oriented Evidence that Matters.

"Breast screening is a particularly emotive area for discussion. Often anecdotal evidence and experience play a greater role in patients' decision making than objective evidence." - POEM 4
They also pointed out that women who have friends and relatives who are healthy following breast cancer treatment will not change their acceptance of routine mammography screening practice. In addition, physicians explained that the majority of women would wish to be screened despite knowing about the drawbacks and harms.

"I suspect the majority of women would prefer to take the risk of having a cancer over-treated rather than miss treating a cancer that required treatment. So what if anything should be done differently?" POEM 1

Figure 1. Themes and subthemes that emerged from physician comments.

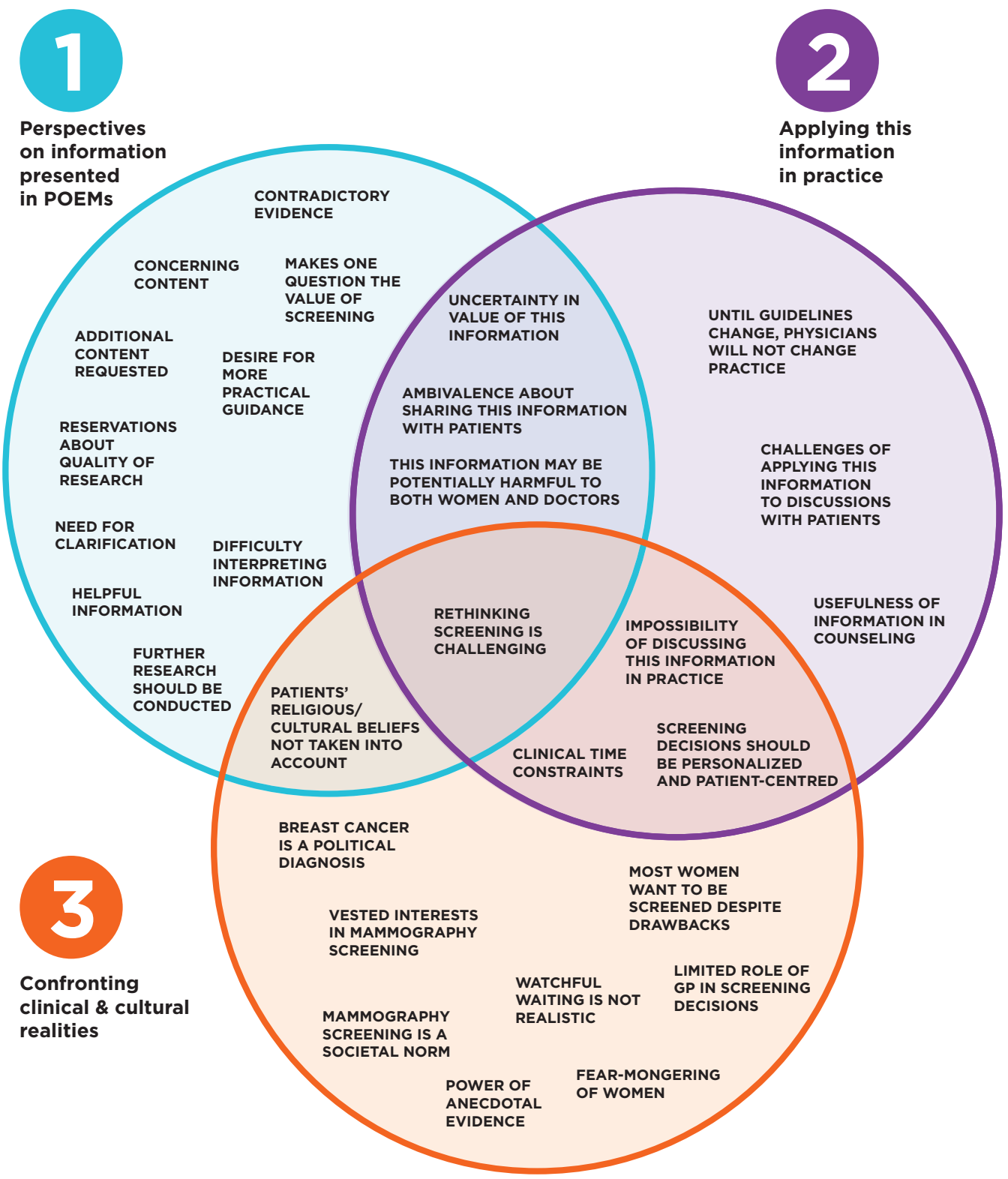


Physicians also indicated many women would rather go through the experience of a false alarm than miss a breast cancer diagnosis.

"Counselling women about breast cancer screening benefits and risks is very difficult. Very few of my patients are able to make an informed choice. Even when my patients have false-positive screens, which require further imaging and biopsies that are negative, they are happy that they were screened. They see it as a 'close call,' and sometimes say, 'It's a good thing I did that' or 'Thank goodness we have this system.'" POEM 4

A considerable number of comments discussed the screening culture in our society. Physicians brought up the 'fear-mongering' of women, for instance, by cancer agencies. Other comments discussed the vested interests in mammography screening, including the government's role in the endorsement of screening. Time was brought up as a barrier to holding balanced discussions with patients based on the information presented in the POEMs. Physicians also situated family physicians within the broader screening picture, pointing out their limited influence on women's decision making due to aggressive marketing of screening programs. Finally, physicians spoke about the importance of personalizing screening decision making, and underscored the importance of shared decision making in their practice.

The results from the analysis of the qualitative data (Figure 1) generally were congruent with those from the quantitative data (Table 3). The reported frequencies of intended use of POEMs information during a discussion with a particular patient (Table 3 ) were over $54 \%$ in the 4 POEMs. The comments showed that a considerable number of physicians were concerned with the various practical uses of this research-based information in discussions with patients. Only 16 of the 310 comments explicitly described possible harms of the research-based information.

\section{Discussion}

Debates about the value of mammography in average-risk women persist due to issues in the quality and trustworthiness of the evidence used to establish claims about outcomes such as disease-specific mortality and overdiagnosis. ${ }^{46}$ Overall, our results confirm this complex screening landscape, and reveal that physicians describe mammography screening for average risk women as a complicated evolving topic. The vast majority of women in
Canada are at average-risk of developing breast cancer, with only $1 \%$ to $2 \%$ of Canadian women being at high risk. ${ }^{47}$ Given the growing doubts about the value of mammography screening and increasing concerns about overdiagnosis, it is crucial to critically examine the thoughts of physicians on the evidence available on these issues.

To our knowledge, our study is the first to use ratings of synthesized evidence as a means of understanding physician perspectives on research-based information regarding mammography screening. This study illustrates convergences and divergences among physicians and elaborates on how physicians perceive their role within the context of organized government-based screening programs.

Physicians' perspectives on information presented in POEMs constitutes the first major theme in the analysis of our data. Although some physicians had knowledge of overdiagnosis and expressed the need for rates to decrease, others asked for clarification regarding the meaning of overdiagnosis, and how one can know which tumors were overdiagnosed. Among the physicians who answered "Yes" to Q3, over $70 \%$ thought that the research-based information would help avoid unnecessary or inappropriate treatment, diagnostic procedures, preventative interventions or referrals for patients. Some physicians, however, brought up the harms of sharing information relating to overdiagnosis with patients.

As part of the second major theme, applying this information in practice, numerous physicians indicated the research-based information could improve conversations with patients. A small number of physicians mentioned that until guidelines change, their screening practices would not change. Regarding these comments, it would have been helpful to know what physicians meant by their practice not changing; if it was in their approach to screening decision making with their patients, or the actual practice of referring patients for mammography screening. Although guidelines can be influential, our study raises questions about the other sources physicians use to make decisions. One group of educators and physicians acknowledged that: "Humans normally make decisions based on their own mental map of information and the internalised tacit guidelines ('mindlines') they construct, largely from brief reading and talking to other people." 48

The creation of and adherence to screening guidelines remain a popular topic of investigation. Norris et $\mathrm{al}^{49}$ examined the relationship between 
screening guideline panel members, their conflicts of interest, and screening recommendations for asymptomatic average-risk women aged 40 to 49 years. They found that 5 of the 8 guideline panels recommending screening had a radiologist member, but none of the 4 guideline panels recommending against routine screening had a radiologist as a panel member. The proportion of primary care physicians on guideline panels recommending nonroutine screening was significantly lower than that of panels that recommended routine screening. Interestingly, none of the clinical bottom lines in the POEMs recommended physicians discontinue mammography screening, but numerous physicians nonetheless expressed their reservations about changing their practice based on this information and reaffirmed their support for screening.

Many of the comments within the third major theme, confronting clinical and cultural realities, discussed a strong screening culture. For example, being a woman entails being the target of 'fear mongering' from advertising on breast cancer screening, and feeling pressured by government agencies. These features of screening culture in North American settings have been described in the literature, notably as one of the drivers of overdiagnosis. ${ }^{50}$ Specifically, physicians in our study commented on the political environment of women's health impeding their ability to discuss screening with women, and the vested interests in mammography screening. Others acknowledged that asking doctors and women to reconsider screening given our culturally ingrained expectations would represent a genuine challenge. Indeed, these realities result in a pressure to screen and leave little room to discuss the drawbacks of screening with patients. Yet Woloshin and Schwartz ${ }^{51}$ affirm that in a world where selling screening is much easier than selling informed choice, women must be reminded that mammography screening is a genuine choice.

Similar to the hormone replacement therapy crises in the early 2000s and subsequent ongoing confusion, it can be difficult to accept that the value of a test like mammography screening can change over time. The study of medical reversals focuses on these challenges, such as abandoning practices that are either deemed no longer effective or deemed to have harms that outweigh the benefits. ${ }^{52,53}$

The data in the third theme also pointed to the power of anecdotal evidence in influencing beliefs around screening. Physicians mentioned that knowing someone who experienced breast cancer seemed to increase the likelihood that an individual would support screening. Raffle and Gray describe this as the "popularity paradox," whereby, the greater the phenomenon of overdiagnosis and overtreatment, the greater become the number of individuals believing they owe their health or their life to the screening program. ${ }^{54}$

Furthermore, the concerns articulated by physicians in our study about time constraints in applying and discussing research-based information with patients have been the focus of some researchers' work. This issue of scarce clinical time led Woolf et $\mathrm{al}^{55}$ to identify ways of learning about decisionmaking preferences by engaging patients outside the clinical setting. Using an online interactive health module, women and men who were either overdue for a screening test or who had not undergone a mammogram or a prostate-specific antigen test were recruited. When it came to screening decisions, participants in this study preferred to first speak to their health provider, second, to read about the screening test, and third, to consult with trusted friends or family. The most frequently reported fears were getting cancer or receiving a delayed diagnosis, followed by abnormal test results, and lastly, testing complications such as false positives or unnecessary treatment. Women eligible for mammography were less likely to express fears about complications from screening tests and less likely to prioritize balancing the harms and benefits over gut feelings, compared with men eligible for prostate-specific antigen testing. This last finding also affirms some of the concerns held by the physicians in our study, about women's prioritization of other forms of knowledge such as anecdotal evidence, over evidence generated from clinical research. Physicians in our study additionally expressed that many women prefer running the risk of an overdiagnosis than a missed diagnosis. This finding is in concordance with the CTFPHC's most recent systematic review, which investigated women's values and preferences. ${ }^{13}$

Shared decision making can allow physicians and their patients to constructively discuss options for a decision while facing these clinical and cultural realities in a patient-centered manner. This decision making approach is currently promoted for decisions such as whether or when to begin mammography screening for average-risk women. ${ }^{56-58}$ 
Patients vary in their desired levels of involvement in screening decisions, ${ }^{59}$ and physicians must keep this diversity of preferences in mind. For example, in our study, one physician shared how surprised they were to discover some of their patients desired a more "paternalistic" approach.

Furthermore, the fact that some physicians in our study were ambivalent about sharing researchbased information should be further examined, given that women need access to trustworthy information for shared decision making. In 2018, Tripp and Abelson ${ }^{60}$ led a series of citizen deliberations across 8 provinces and 2 territories in Canada to discuss the current state of evidence on mammography screening. Through these deliberations, the authors sought to understand women's perspectives on educational materials developed by governmentbased screening programs to support informed decision making. Their study revealed that women found this information to be insufficient, and as a result found themselves unable to make fully informed decisions. In identifying what key features would make such information optimal, the participants called for education material to be: accessible, consistent, complete and accurate, and to contain information on both harms and benefits, and communicated in an easy to understand way. Until such materials are developed, our study further emphasizes the crucial need for primary providers to provide balanced, up-to-date knowledge to help their patients make decisions about controversial medical topics.

Despite having access to evidence, not all physicians seem equipped with the knowledge and tools to discuss it, especially when the evidence is uncertain. In a study by Dubenske et $\mathrm{al}^{61}{ }^{61}$ a disconnect was revealed between patient expectations about physicians' understanding of screening guidelines, and physician's confidence in shared decision making with regard to mammography screening. Furthermore, findings from Smith et $\mathrm{al}^{31}$ suggest that women are not necessarily getting the opportunity to discuss screening in the way and at the time they would like. These concerns must be addressed to improve patient care. Among available resources for supporting personalized decision making, validated decision aids are increasingly used and recommended to fill gaps in understanding. An update of a Cochrane systematic review of 105 studies on the effects of decision aids showed that individuals exposed to decision aids felt better informed than those who had usual care. ${ }^{62}$ This review also found that decision aids reduced the number of undecided participants and seemed to improve communication between patients and providers. A randomized controlled trial of screening decision making using 2 different decision aids showed that when women were exposed to information about over detection of breast cancer, fewer women had positive attitudes toward mammography. ${ }^{45}$

Regardless of whether a physician shares the information contained in the POEMs and uses a decision aid with patients, our study pointed to the strong influence of other factors on the discussion between a physician and their patient about mammography screening. Several factors were revealed in a critical interpretive review of literature reporting primary care providers' perspectives and approaches on mammography screening with averagerisk women. These include, among others: lack of clinical time, organizational guidelines, patients' requests for screening, patients' anxiety about breast cancer, physicians' colleagues' and mentors' practices, and the fear of missing potentially lethal cancers. ${ }^{63}$ Finally, data from our study concord with those from this aforementioned critical interpretive review on the importance of building trusting relationships to improve patient experience around screening decision making.

\section{Implications}

This study has important implications for practice, future research, and policy. Physicians' intent to use the research-based information to support more nuanced screening discussions and to prevent unnecessary testing and treatment suggests the potential of this information to promote more informed-decision making and to reduce overdiagnosis.

Our results reveal challenges experienced by physicians in understanding and explaining evidence about screening and overdiagnosis of breast cancer. These challenges should be addressed in follow-up investigations. Our research gives consideration to the constant evolution of evidence on mammography screening and points to the difficulty physicians face in deciding what information should be shared with average-risk women considering screening. Despite continuing controversies in mammography screening, physicians expressed the importance of optimizing decision making and respecting women's personal values and preferences for screening. Until further clarity is reached, 
researchers and medical professionals are increasingly pointing to the need for shared decision making in navigating mammography screening decisions. ${ }^{64}$ This body of work should continue to look at clear ways of implementing shared decision making between primary care providers and their patients.

In addition, this study clearly shows that factors external to the patient-provider context influence women's and physician's screening beliefs and approaches. For instance, women who do not have a family physician yet are invited to screening by mail effectively have no opportunity to discuss mammography screening with a trusted professional before screening. Further consideration should be given to such factors.

\section{Limitations}

First, the free text box in the last section of the IAM questionnaire, from which we extracted the majority of the qualitative data, does not prompt physicians with a specific question. This format allows for a wide range of responses to emerge. Despite this, the free text box encouraged some physicians to submit diverse and rich responses.

Second, the quantitative data pertaining to the intended use of the research-based information reflect physicians' thoughts at a single moment in time. These intentions to use the information at a given moment may not necessarily represent what physicians will actually do later, in practice. To our knowledge, there have been no follow-up studies to assess physician behavior change in practice following a specific POEM; this offers an interesting avenue for future research.

Third, although over 1000 physicians rated each of the 4 POEMs in this study, only a smaller number provided comments on which our qualitative analysis was based. Although a larger number of comments may have provided greater insight into the topics discussed, we believe that 310 comments still provides an acceptable overview of physician perspectives for a first study based on POEMs using qualitative data.

Lastly, it was not feasible to link demographic information about individual physicians to their comments and ratings for each POEM. Practice settings and patient populations vary from physician to physician and not knowing the specific demographics of the participating physicians does limit the generalizability of our findings. However, analysis of the demographics of physicians who rated
POEMs in 2014 showed the majority were in general or family practice. ${ }^{36}$ Despite limited data to describe these physician respondents, our study results are valuable in that they provide a unique overview of physician perspectives from a geographically dispersed group of physicians in Canada.

\section{Conclusion}

This study explored physicians' perspectives on information about mammography screening for average-risk women presented in POEMs, and the ways physicians may use this information in their clinical practice. Although research-based information in the form of a POEM may be helpful in counseling average-risk women about screening and in offering a more balanced view of harms and benefits, deeply rooted ideas seem to stall opportunities for shifts in perspectives and clinical practice. The central theme identified in this study can be summarized as follows: rethinking breast cancer screening for average-risk women is challenging.

The authors wish to thank Joule, Inc. for their support of an ongoing continuing medical education program in which members of the Canadian Medical Association rate the daily POEM.

To see this article online, please go to: http://jabfm.org/content/ 33/6/871.full.

\section{References}

1. Myers ER, Moorman P, Gierisch JM, et al. Benefits and harms of breast cancer screening: a systematic review. JAMA 2015;314:1615-34.

2. The Canadian Partnership Against Cancer. Cancer screening programs across Canada. 2018. Available from: https://www.partnershipagainstcancer.ca/ topics/breast-cancer-screening-environmentalscan-2018/.

3. Plutynski A. Ethical issues in cancer screening and prevention. J Med Philos 2012;37:310-23.

4. Welch HG, Passow HJ. Quantifying the benefits and harms of screening mammography. JAMA Intern Med 2014;174:448-54.

5. Welch HG, Black WC. Overdiagnosis in cancer. JNCI 2010;102:605-13.

6. Biller-Andorno N, Jüni P. Abolishing mammography screening programs? a view from the Swiss Medical Board. N Engl J Med 2014;370:1965-7.

7. Barratt A, Jørgensen K, Autier P. Reform of the national screening mammography program in france. JAMA Intern Med 2018;178:177-8.

8. Andersson I, Sigfusson B. Screening for breast cancer in Malmö: a randomized trial. Breast Cancer. Recent Results Cancer Res 1987;105:62-6. 
9. Nyström L, Bjurstam N, Jonsson H, Zackrisson S, Frisell J. Reduced breast cancer mortality after 20+ years of follow-up in the Swedish randomized controlled mammography trials in Malmö, Stockholm, and Göteborg. J Med Screen 2017;24:34-42.

10. Gøtzsche PC, Jørgensen KJ. Screening for breast cancer with mammography. Cochrane Database Syst Rev 2013;2013:CD001877.

11. Juth N, Munthe C. The ethics of screening in health care and medicine: serving society or serving the patient? Berlin, Germany: Springer Science \& Business Media; 2011.

12. The Independent Panel on UK Breast Cancer Screening. The benefits and harms of breast cancer screening: an independent review. Lancet 2012;380: 1778-86.

13. Klarenbach S, Sims-Jones N, Lewin G, et al. Recommendations on screening for breast cancer in women aged 40-74 years who are not at increased risk for breast cancer. Can Med Assoc J 2018;190: E1441-E1451.

14. Hoffmann TC, Del Mar C. Clinicians' expectations of the benefits and harms of treatments, screening, and tests: a systematic review. JAMA Intern Med 2017;177:407-19.

15. Wegwarth O, Schwartz LM, Woloshin S, Gaissmaier W, Gigerenzer G. Do physicians understand cancer screening statistics? A national survey of primary care physicians in the United States. Ann Intern Med 2012;156:340-9.

16. The Canadian Task Force on Preventive Health Care. Recommendations on screening for breast cancer in average-risk women aged 40-74 years. Can Med Assoc J 2011;183:1991-2001.

17. The Canadian Institute for Health Information. Unnecessary Care in Canada. 2017. Available from: https://www.cihi.ca/sites/default/files/document/ choosing-wisely-baseline-report-en-web.pdf.

18. Moynihan R, Doust J, Henry D. Preventing overdiagnosis: how to stop harming the healthy. BMJ 2012;344:e3502.

19. Rogers WA, Mintzker Y. Casting the net too wide on overdiagnosis: benefits, burdens and non-harmful disease. J Med Ethics 2016;42:717-103715.

20. Morris E, Feig SA, Drexler M, Lehman C. Implications of overdiagnosis: impact on screening mammography practices. Pop Health Manag 2015;18: S3-S11.

21. Barratt A. Overdiagnosis in mammography screening: a 45 year journey from shadowy idea to acknowledged reality. BMJ 2015;350:h867-h867.

22. Baines CJ, To T, Miller AB. Revised estimates of overdiagnosis from the Canadian National Breast Screening Study. Prev Med 2016;90:66-71.

23. De Gelder R, Heijnsdijk EA, Van Ravesteyn NT, Fracheboud J, Draisma G, De Koning HJ. Interpreting overdiagnosis estimates in population- based mammography screening. Epidemiol Rev 2011;33:111-21.

24. Coldman A. Overdiagnosis of breast cancer associated with screening mammography. North American Association of Central Cancer Registries. 2014. Ottawa, Canada. Available from: https://www.naaccr. org/wp-content/uploads/2016/11/PLENARY-625-14NAACCR-2014-SES-Coldman.pdf.

25. Loeb S, Bjurlin MA, Nicholson J, et al. Overdiagnosis and overtreatment of prostate cancer. Eur Urol 2014;65:1046-55.

26. Cassel CK, Guest JA. Choosing wisely: helping physicians and patients make smart decisions about their care. JAMA 2012;307:1801-2.

27. Ebell MH, Thai TN, Royalty KJ. Cancer screening recommendations: an international comparison of high income countries. Public Health Rev 2018;39:7.

28. Miller JW, Baldwin LM, Matthews B, et al. Physicians' beliefs about effectiveness of cancer screening tests: a national survey of family physicians, general internists, and obstetrician-gynecologists. Prev Med 2014;69:37-42.

29. Meissner HI, Klabunde CN, Han PK, Benard VB, Breen N. Breast cancer screening beliefs, recommendations and practices: primary care physicians in the United States. Cancer 2011;117:3101-11.

30. Scheel JR, Hippe DS, Chen LE, et al. Are physicians influenced by their own specialty society's guidelines regarding mammography screening? An analysis of nationally representative data. Am J Roentgenol 2016;207:959-64.

31. Smith P, Hum S, Kakzanov VD, Giudice ME, Heisey R. Physicians' attitudes and behaviour toward screening mammography in women 40 to 49 years of age. Can Fam Physician 2012;58:e508-e13.

32. Tudiver F, Guibert R, Haggerty J, et al. What influences family physicians' cancer screening decisions when practice guidelines are unclear or conflicting? J Fam Pract 2002;51:760.

33. Haggerty J, Tudiver F, Brown JB, Herbert C, Ciampi A, Guibert R. Patients' anxiety and expectations: how they influence family physicians' decisions to order cancer screening tests. Can Fam Physician 2005;51:1658-9.

34. Chamot E, Charvet A, Perneger TV. Women's preferences for doctor's involvement in decisions about mammography screening. Med Decis Making 2004;24:379-85.

35. Grad R, Pluye P, Tang D, Shulha M, Slawson DC, Shaughnessy AF. Patient-Oriented Evidence that Matters $(\mathrm{POEMs})^{\mathrm{TM}}$ suggest potential clinical topics for the Choosing Wisely ${ }^{\mathrm{TM}}$ campaign. J Am Board Fam Med 2015;28:184-9.

36. Grad RO, Tang DLP. POEMs reveal candidate clinical topics for the Choosing Wisely Campaign. Preventing Overdiagnosis Conference. Bethesda, MD, September 2015. 
37. Grad RM, Pluye P, Mercer J, et al. Impact of research-based synopses delivered as daily e-mail: a prospective observational study. J Am Med Inform Assoc 2008; 15:240-5.

38. Badran H, Pluye P, Grad R. When educational material is delivered: a mixed methods content validation study of the information assessment method. JMIR Med Educ 2017;3:e4.

39. Braun V, Clarke V. Using thematic analysis in psychology. Qualitative Res Psychol 2006;3:77-101.

40. NVivo. NVivo qualitative data analysis Software; QSR International Pty Ltd. Version 11.4.1. 2016.

41. Pluye P, Grad R, Repchinsky C, et al. "Better-thanbest” evidence? Using family physicians' feedback for 2-way knowledge translation. Can Fam Physician 2014;60:415-7.

42. Bleyer A, Welch HG. Effect of three decades of screening mammography on breast-cancer incidence. N Engl J Med 2012;367:1998-2005.

43. Brodersen J, Siersma VD. Long-term psychosocial consequences of false-positive screening mammography. Ann Fam Med 2013;11:106-15.

44. Miller AB, Wall C, Baines CJ, Sun P, To T, Narod SA. Twenty-five year follow-up for breast cancer incidence and mortality of the Canadian National Breast Screening Study: randomised screening trial. BMJ 2014;348:g366.

45. Hersch J, Barratt A, Jansen J, et al. Use of a decision aid including information on overdetection to support informed choice about breast cancer screening: a randomised controlled trial. Lancet 2015;385:1642-52.

46. Cifu AS, Prasad VK. Medical debates and medical reversal. J Gen Intern Med 2015;30:1729-30.

47. Canadian Cancer Society. Being high risk for breast cancer. 2017. Available from: http://www.cbcf.org/ ontario/AboutBreastHealth/Being-High-Risk/Pages/ default.aspx.

48. Hutchinson A, Slawson DC, Shaughnessy A, Underhill A. Information mastery decision-making and dealing with information overload. In: Mehay R, ed. The essential handbook for GP training and education. London, UK: Radcliffe Publishing; 2012.

49. Norris SL, Burda BU, Holmer HK, et al. Author's specialty and conflicts of interest contribute to conflicting guidelines for screening mammography. J Clin Epidemiol 2012;65:725-33.

50. Pathirana T, Clark J, Moynihan R. Mapping the drivers of overdiagnosis to potential solutions. BMJ 2017;358:j3879.
51. Woloshin S, Schwartz LM. Numbers needed to decide. J Natl Cancer Inst 2009;101:1163-5.

52. Prasad V, Cifu A. Medical reversal: why we must raise the bar before adopting new technologies. Yale J Biol Med 2011;84:471-8.

53. Sutton D, Qureshi R, Martin J. Evidence reversalWhen New evidence contradicts current claims: a systematic overview review. J Clin Epidemiol 2018; 94:76-84.

54. Raffle AE, Gray JM. Screening: evidence and practice. Oxford, UK: Oxford University Press; 2007.

55. Woolf SH, Krist AH, Lafata JE, et al. Engaging patients in decisions about cancer screening: exploring the decision journey through the use of a patient portal. Am J Prev Med 2018;54:237-47.

56. Bell NR, Grad R, Dickinson JA, et al. Better decision making in preventive health screening. Balancing benefits and harms. Can Fam Physician 2017;63: 521-4.

57. Grad R, Légaré F, Bell NR, et al. Shared decision making in preventive health care: what it is; what it is not. Can Fam Physician 2017;63:682-4.

58. Blair L, Légaré F. Is shared decision making a utopian dream or an achievable goal? Patient 2015;8:471-6.

59. Nekhlyudov L, Ross-Degnan D, Fletcher SW. Beliefs and expectations of women under 50 years old regarding screening mammography: a qualitative study. J Gen Intern Med 2003;18:182-9.

60. Tripp L, Abelson J. Supporting women at average risk to make informed decisions about mammography when there is no "right" answer: a qualitative citizen deliberation study. CMAJ Open 2019;7: E730-E737.

61. DuBenske LL, Schrager S, McDowell H, Wilke LG, Trentham-Dietz A, Burnside ES. Mammography screening: gaps in patient's and physician's needs for shared decision making. Breast J 2017;23:210-4.

62. Stacey D, Légaré F, Lewis K, et al. Decision aids for people facing health treatment or screening decisions. The Cochrane Library 2017;4:CD001431.

63. Siedlikowski S, Ells C, Bartlett G. Scrutinizing screening: a critical interpretive review of primary care provider perspectives on mammography decision-making with average-risk women. Pub Health Rev 2018;39:15 Dec 1.

64. Keating NL, Pace LE. Breast cancer screening in 2018: time for shared decision making. JAMA 2018;319:1814-5. 